\title{
Assessment of an expanded-polypropylene isothermal box to improve logistic sustainability of catering services
}

\author{
Andrea Casson, Valentina Giovenzana, Alessio Tugnolo, Alessia Pampuri, Ilaria Fiorindo, Roberto Beghi, \\ Riccardo Guidetti \\ Department of Agricultural and Environmental Sciences - Production, Landscape, Agroenergy, Università degli Studi \\ di Milano, Milano, Italy
}

\begin{abstract}
The European catering sector is hugely expanding and serves over 6 billion meals every year, which translate in 65 million meals per day. The aim of our study was to investigate the environmental performance of the expanded-polypropylene (EPP) box production process to improve sustainability in catering services. Moreover, a quantification of the environmental benefit in using the EPP box instead of the conventional packaging was performed.

The life cycle assessment was conducted following the ISO 14044:2006 standard. The EPP box for food delivery makes it possible to design a catering service characterised by $-37 \%$ of overall impacts compared to the use of the common box. EPP represents a useful solution for environmentally sustainable catering services due to its mechanical response and the insulating properties of the polymer foam. The environmental impact of the EPP box life cycle can be further reduced $(-29 \%)$ by changing the energy country mix and applying a circular economy model, thus recycling the $100 \%$ of the EPP box. In conclusion, the EPP box represents a useful solution for an environmentally sustainable catering service.
\end{abstract}

\footnotetext{
Correspondence: Valentina Giovenzana, Department of Agricultural and Environmental Sciences - Production, Landscape, Agroenergy, Università degli Studi di Milano, via Celoria 2, 20133 Milano, Italy. E-mail: valentina.giovenzana@unimi.it
}

Key words: Food service; delivery service; design; circular economy; life cycle assessment; environmental impact.

Acknowledgements: the authors wish to thank Polibox ${ }^{\circledR}$ - Gruppo SDS srl company for the technical support.

Received for publication: 12 December 2020.

Accepted for publication: 17 May 2021.

${ }^{\circ}$ Copyright: the Author(s), 2021

Licensee PAGEPress, Italy

Journal of Agricultural Engineering 2021; LII:1139

doi:10.4081/jae.2021.1139

This article is distributed under the terms of the Creative Commons Attribution Noncommercial License (by-nc 4.0) which permits any noncommercial use, distribution, and reproduction in any medium, provided the original author(s) and source are credited.

\section{Introduction}

Logistics and supply chain management play a crucial role in the food industry. In 2013 Manzini and Accorsi proposed an integrated approach to study the food supply chain in order to design and manage simultaneously quality, safety, sustainability and logistics efficiency of food products and processes from farm to fork. In particular, the European catering sector serves over 6 billion meals every year, which translates into 65 million meals per day (FERCO, 2014). This sector is characterized by two approaches: conventional or cook-serve and deferred. In the conventional systems, the meals are cooked and immediately served to consumers (Ciappellano et al., 2009), whereas according to the deferred method, used in the most of the recent catering contracts, meals are prepared in a centralized cooking centre and then delivered to schools, hospitals, universities, and companies depending on the type of contract (Fusi et al., 2016; García-Herrero et al., 2019). The distinctive element of the differed system is that the time difference between the preparation in the centralized cooking centre and the consumption can be several hours or days. In this approach, three types of chains can be used: i) cook-warm; ii) cook-chill; and iii) cook-freeze (Williams et al., 1996; Ciappellano et al., 2009). Each one has well-defined procedures to identify the best practices for serving meals, considering the restrictions in term of time between preparation and consumption and acceptable temperature drops to ensure food safety (Williams et al., 1996). Besides food safety parameters, catering services are transitioning towards a more sustainable way of feeding their target groups (Baldwin et al., 2011; Palacios-Argüello et al., 2018; Saxe et al., 2019). For instance, they purchase energy-efficient kitchen equipment, use tap water, transport food using vehicles with a low environmental impact, and reduce significantly the use of packaging (Balzaretti et al., 2018). Also, the Green Public Procurements initiative by the European Commission (Neto et al., 2017) set out new environmental criteria based on the quality of food processing practices. However, if sustainability practices are based only on criteria related to quality and not quantity and environmental performance (greenhouse gasses, water depletion, or resource consumption), it is impossible to calculate the actual environmental savings (Cerutti et al., 2016).

The life cycle assessment (LCA) was applied to some food products (Roy et al., 2009) emphasizing the importance of cleaner production techniques (Silva and Sanjuán, 2019). Recent studies analysed various catering services using the LCA, focusing on the environmental impacts of the deferred approach and evaluating different options for food preparation and distribution (Fusi et al., 2016; Cerutti et al., 2018; Mistretta et al., 2019; García-Herrero et al., 2019). These studies highlighted the environmental impact due to the logistics and transport of the meals from the centralized cooking centre to the satellite kitchens. García-Herrero et al. (2019) calculated that the delivery method account for 3\% and 
$12 \%$ of the total environmental impact of a meal, representing high responsibility of environmental impact. Giordano et al. (2014) reported that impact of transport could be lowered from $35 \%$ up to $99 \%$ by replacing current vans with electric ones (which would translate into high reorganization costs) and/or optimizing meal logistics (vehicle loads, equipment and containers used).

In recent years, new materials and products have started to offer a valid alternative to the traditional equipment in the logistic sector (heavy trolleys, heavy boxes and heated or even refrigerated vans). According to the Regulation EC No.1935/2004 on foodgrade materials and items (European Union, 2004) and its environmental impact, tertiary packaging should be both efficient, as it can minimize the use of materials, energy and resources depletion, and effective, as it can maximize its positive role in terms of food preservation (Licciardello, 2017).

In this scenario, expanded polypropylene (EPP) represents a useful solution. This raw material (Xu et al., 2007; Zhai et al., 2010, 2011; Yu et al., 2013) can be used to make crates and boxes for transport and storage in order to replace the conventional materials adopted for catering logistics. EPP boxes represent a valid solution for delivery of meals from the centralised cooking centre to the satellite kitchens due to the mechanical properties of this material (Lopes et al., 2019; Morton et al., 2020), to its suitability for packaging more sensitive goods (Raps et al., 2014), its foodgrade quality (Srivastava and Srivastava, 2014), and its ability to protect food from thermal stress due to the insulating properties of polymeric foam (Zhai et al., 2010, 2011).

The aim of the study was to investigate the environmental performance of the expanded-polypropylene (EPP) box production process for the purpose of identifying engineering aspects to design more sustainable catering services. The benefit of replacing conventional materials with the EPP box was calculated. The LCA was used as a decision-making tool for the calculation of the environmental impact of the potential choices in catering service design.

\section{Materials and methods}

The LCA proposed in this study was performed according life cycle assessment standards (ISO 14040-14044: 2006). The entire study was conducted by using the LCA software Simapro 9 (PRé Sustainability, Amersfoort, The Netherlands) and the Ecoinvent 3.5 database.

\section{Goal and scope}

The LCA study was performed to: i) evaluate the environmental impact of the EPP box; and ii) evaluate and compare the environmental impact of the delivery service bases on EPP boxes $v s$ common isothermal boxes.

The functional unit (FU) was defined as one packaging product unit (one EPP isothermal box) with specific characteristic as reported in Table 1.

The packaging box analysed offers a safe environment which ensures food health and hygiene parameters as well as high mechanical and thermal protection during the delivery process.

The isothermal box is obtained from EPP, a non-toxic, lightweight, durable and fully recyclable material. It can be defined as reusable tertiary packaging, which can be used to deliver hot and cold food products in Gastronorm 1/1 (GN 1/1) or bulk.

The boundary system from cradle to grave was considered to analyse the life cycle phases of the EPP box, from polypropylene (PP) extraction, its expansion in EPP to the waste management processes. As reported in Figure 1, the reference flow consisted of three modules: upstream, core and downstream. The extraction of PP and its expansion to make EPP were defined in the upstream module. The production process was identified in the core module, starting from the transport of the EPP beads to the production plant and ending with the packing of the EPP box. The downstream module included the transportation, and disposal of the EPP box. The catering service considered only the logistic aspects linked to the delivery service. Primary data were collected for core and downstream modules with surveys and interviews, while secondary data was used for the upstream module and the end-of-life scenario.

According to ISO 14044, the allocation refers to the partitioning of the input and output flows of a process or a product system between the product/system under study and one or more additional products (ISO 14044:2006). The study analysed the production of a tertiary box used for the logistic channel of catering services following the environmental significance allocation criteria.

Due to the variability of the delivery service phase (e.g. different distances), the use phase will be analysed separately from the LCA of the production process. In particular, the comparison was conducted based on an application model related to a school catering service (paragraphs 2.2.3 and 2.4) to highlight the effects of replacing standard boxes with EPP boxes.

\section{Life cycle inventory}

Data concerning the EPP box production phases (core module) and the downstream distribution phase were collected via questionnaires and surveys submitted to a company by the name of Polibox ${ }^{\circledR}$ - Gruppo SDS for the analysis of primary data. Conversely, secondary data was used for the upstream and end-oflife phase inputs. A comparison between the use of EPP box and a standard one was performed to evaluate potential environmental benefits in the catering service.

\section{Upstream module}

Extraction and expansion of polypropylene

Extraction of polypropylene and its expansion in EPP was modelled using secondary data (Ecoinvent 3.5 database).

In a typical PP foaming process, a high-pressure vessel is used. A certain amount of $\mathrm{CO}_{2}$ was used as expanding agent. Heat is also used to achieve the saturation temperature to obtain the sorption of $\mathrm{CO}_{2}$ in PP pellets. Once the sorption of $\mathrm{CO}_{2}$ into the PP pellets reached the equilibrium level, $\mathrm{CO}_{2}$ in the high-pressure vessel was released from the foaming pressure into the ambient pressure. During this release, PP beads expand (Xu et al., 2007). According to the FU identified, the quantity of raw material necessary to obtain FU was calculated.

Table 1. Structural and mechanical characteristics of the expanded-polypropylene box.

\begin{tabular}{lcc} 
Dimension & Amount & Unit of measure \\
Width & 400 & $\mathrm{~mm}$ \\
Length & 600 & $\mathrm{~mm}$ \\
\hline Height & 270 & $\mathrm{~mm}$ \\
Volume & 38.6 & $\mathrm{dm}^{3}$ \\
\hline Weight & 768 & $\mathrm{~g}$ \\
Temperature range & $-40 /+120$ & ${ }^{\circ} \mathrm{C}$ \\
\hline Resistivity coefficient & 0.039 & $\mathrm{~W} / \mathrm{mK}$ \\
$75-65^{\circ} \mathrm{C}$ drop time & +180 & minutes \\
\hline
\end{tabular}




\section{Core module}

\section{Expanded-polypropylene beads transportation}

EPP beads were transported to the processing company by a 20-feet-long truck (ISO 668:2020). The product transported had a very low density $\left(25 \mathrm{~kg} \mathrm{~m}^{-3}\right)$, thus posing a volume limit $\left(82 \mathrm{~m}^{3}\right)$, regardless of the loading weight capacity of the truck (16 t). For this reason, the product transported filled the trailer, but it weighed only $2100 \mathrm{~kg}$. The average distance between the extraction site and the production site was 1054 kilometres.

\section{Expanded-polypropylene bead storage}

The EPP was received at the company and stored into silos after passing quality controls. The EPP beads were moved from the truck to the silos using a vacuum pump $(11 \mathrm{~kW})$ with a flow rate of $1080 \mathrm{~kg} \mathrm{~h}^{-1}$ for the EPP analysed.

According to the allocation (ISO 14044:2006), Eq. 1 was followed to evaluate the correct amount of electricity to be allocated to the FU.

$E c=\left(M p w^{*} E P P m\right) / F r$

where:

$E c$ : Electricity consumption of the machinery;

$M p w$ : machinery power;

EPPm: EPP mass;

Fr: flow rate of the EPP through the machinery.

\section{Filling}

A second vacuum pump $(7.5 \mathrm{~kW})$ moved the EPP beads from the silos to a pressurization tank. The recorded bead flow was 1720 $\mathrm{kg} \mathrm{h}^{-1}$ and the electricity allocated to the FU was defined based on Equation 1.

\section{Pressurization}

The EPP beads were fed into the pressurization tank $\left(45 \mathrm{~m}^{3}\right)$ to reach $3 / 4$ of the tank volume (about $900 \mathrm{~kg}$ of EPP). Subsequently, an air compressor $(250 \mathrm{~kW}$ ) was used to pump compressed air in the production line. The air compressor $\left(2430 \mathrm{~m}^{3} \mathrm{~h}^{-1}\right.$ airflow at 7.5 bar) supplied a maintenance chamber set at 7 bar which then sent compressed air at 2.19 bar into the pressurized tanks. The production site was equipped with 6 pressurized tanks operating simultaneously. The pressurized air system was set to ensure 2.19 bar and an airflow of $46 \mathrm{~m}^{3} \mathrm{~min}^{-1}$ per each tank. The air compressor worked for $21.4 \%$ of each production cycle at the maximum power $(240 \mathrm{~kW})$ vs $78.6 \%$ at its minimum power $(80 \mathrm{~kW})$. Hence, the final air compressor power load was $114.24 \mathrm{~kW}$. the electricity consumption of the air compressor per FU was quantified on the basis of the flow rate of the production site $\left(100\right.$ boxes $\left.^{-1}\right)$.

\section{Steam chest moulding}

The moulding phase, which is the most important stage of the production phase, followed the sintering process and was operated with three input flows: EPP, compressed air, and steam (Zhai et al., $2010,2011)$. The company in this case study was equipped with 5 moulding presses $(13 \mathrm{~kW})$ having flow rate of 20 boxes per hour.

The steam chest moulding process included the following steps: i) closing; ii) filling the mould; iii) steaming; iv) cooling; and v) ejection of the moulded box (Raps et al., 2014). The energy consumption of the press per each FU was assessed.

As to the steam, the 2018 gas and water consumption reports was used to evaluate the amount of gas and water used and according to yearly productivity, the allocated quantity of methane gas and water per FU was determined.

After the ejection of the moulded box, an average of $2 \%$ of the EPP material was lost due to production waste. This waste cannot be reinserted in the production line as raw material and therefore it was treated as plastic waste.

\section{Thermal stabilization}

The moulded boxes then underwent thermal stabilization in an

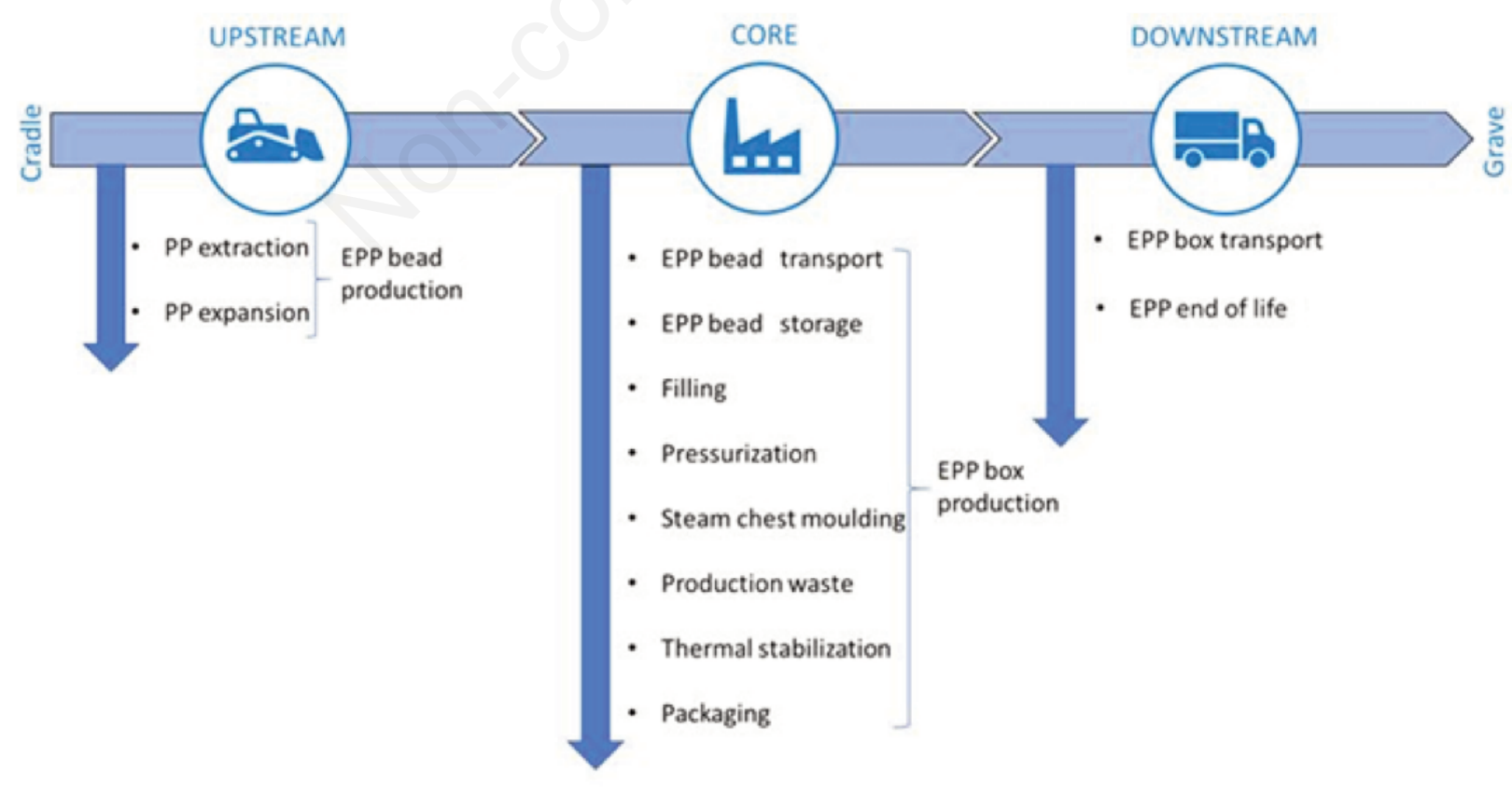

Figure 1. Modules and relative phases considered in the studied system according to the cradle-to-grave boundary system. EPP, expanded-polypropylene. 
oven $(15 \mathrm{~m}$-long $\times 5 \mathrm{~m}$-wide $\times 2.6 \mathrm{~m}$-high $)$ with a capacity of 1050 boxes per cycle. The heat generated by the steamer was recovered and used to maintain a temperature of $75^{\circ} \mathrm{C}$ in the oven. The allocated electricity consumption of the oven per FU was calculated only with reference the two vents $(1.5 \mathrm{~kW}$ each) necessary to stabilize thermally the EPP box.

\section{Packaging}

After thermal stabilization and cooling, the boxes were packed in a PE packaging bag ( $35 \mathrm{~g})$ with a capacity of 5 boxes each and then stacked on a $1200 \times 1100-\mathrm{mm}$ pallet $(14.2 \mathrm{~kg})$ with a capacity of 10 bags.

\section{Downstream module}

\section{Expanded-polypropylene box transportation}

The final destinations of the boxes were spread all over Europe. According to the surveys, $411 \mathrm{~km}$ was the average distance travelled by each 20 -feet truck.

Considering a fully loaded trailer, 22 pallets can be loaded and the average load per FU was defined on the basis of the weight of the box $(768 \mathrm{~g})$ plus the allocated weight of the PE bag $(7 \mathrm{~g})$ plus the allocated weight of the pallet $(284 \mathrm{~g})$.

\section{Catering service}

The company guaranteed the lifetime of the isothermal box for 5 years, during which the isothermal box was used for the delivery phase of the catering service.

\section{Expanded-polypropylene end of life}

Primary data regarding the end-of-life scenario were not collected. Therefore, in order to have representative waste management data, the European plastic packaging waste management scenario was considered (40.8\% recycling, 38.8\% incinerator and 20.4\% landfill) (PlasticsEurope, 2018).

Based on the LCI analysis, the primary input data were calculated and summarized in Table 2.

\section{Sensitivity analysis}

Considering the nature of the process, the sensitivity analysis aimed firstly to evaluate the environmental benefit in replacing the actual Italian energy country mix (45\% natural gas, $16.3 \%$ hydroelectric, $9.3 \%$ coal, $9 \%$ biomass, $8.3 \%$ solar, $6.2 \%$ other fossil fuels and $6.2 \%$ wind) (Deloitte, 2019) with an ideal one based on $100 \%$ renewable electricity sources $(50 \%$ hydroelectric, $20 \%$ photovoltaic, $20 \%$ wind, $10 \%$ geothermal). Secondly, considering the full recyclability of the EPP box, the sensitivity analysis aimed to evaluate the potential benefits of recycling completely the EPP box.

\section{Comparative analysis}

The comparative analysis aimed identify and quantify only the environmental benefit of the delivery phase from replacing the EPP box with a common packaging box in a five-year school catering service. Generally, food products are delivered using isothermal polyethylene (PE) boxes with an average weight of $5 \mathrm{~kg}$. The weight of the isothermal boxes in the food handling phases plays a crucial role in the overall sustainability of the delivery operation, especially if substituted with the EPP box weighting only $768 \mathrm{~g}$. Therefore, the comparison considered only weight differences, neglecting the environmental impact of the raw material and the production processes for both boxes. The modelled system considered a school catering service consisting of 230 working days in which the delivery company handled 1344 food serves daily using a lightweight commercial vehicle (volume capacity of $6.3 \mathrm{~m}^{3}$ per 48 boxes). Each box consisted of an average of $10.64 \mathrm{~kg}$ including one food tray GN 1/1 (2.24 kg) and food (8.4 kg of pasta with tomato sauce). Overall, the daily gross weight transported on the outward trip was $547 \mathrm{~kg}$ in the EPP box scenario including 403.2 $\mathrm{kg}$ of food to be served to the users (net weight), and $750.7 \mathrm{~kg}$ in the common box scenario including $403.2 \mathrm{~kg}$ of food to be served to the users (net weight). Due to weight loss, during the return trip, the lightweight commercial vehicle carried only the boxes and the empty trays, i.e. $144.4 \mathrm{~kg}$ in the EPP box catering service scenario and $347.5 \mathrm{~kg}$ in the PE box catering service scenario. The kilometres covered by the vehicle during the school catering service was $10 \mathrm{~km}$ for the outgoing and return trips.

Table 2. Specifications and quantifications of input data deriving from life cycle inventory analysis.

\begin{tabular}{|c|c|c|c|c|}
\hline EPP box phases & Input & Value & Units & Specifications \\
\hline \multicolumn{5}{|c|}{ Upstream } \\
\hline $\begin{array}{l}\text { Extraction and expansion } \\
\text { of polypropylene }\end{array}$ & EPP beads & 0.776 & $\mathrm{~kg}$ & Quantity of raw material per FU \\
\hline \multicolumn{5}{|c|}{ Core } \\
\hline EPP bead transport & EPP beads transported & 0.776 & $\mathrm{~kg}$ & Weight for FU \\
\hline EPP bead storage & Vacuum pump electricity consumption & 7.89 & Wh & The allocated value for the vacuum pump \\
\hline Filling & Vacuum pump electricity consumption & 3.395 & Wh & The allocated value for the vacuum pump \\
\hline Pressurization & Air compressor electricity consumption & 1.14 & $\mathrm{kWh}$ & The allocated value for the air compressor \\
\hline Steam chest moulding & $\begin{array}{l}\text { Energy consumption of one moulding press } \\
\text { Water } \\
\text { Methane gas } \\
\text { Production waste }\end{array}$ & $\begin{array}{c}151 \\
18 \\
1.60 \\
8\end{array}$ & $\begin{array}{l}\text { Wh } \\
\mathrm{dm}^{3} \\
\mathrm{~m}^{3} \\
\mathrm{~g}\end{array}$ & $\begin{array}{l}\text { The allocated value for one moulding press } \\
\text { The allocated value for one moulding press } \\
\text { The allocated value for one moulding press } \\
\text { EPP beads }\end{array}$ \\
\hline Thermal stabilization & Electricity consumption of the oven & 8.6 & Wh & The allocated electricity consumption per FU \\
\hline Packaging & PE film and pallet & 0.291 & $\mathrm{~kg}$ & The allocated packaging per FU \\
\hline \multicolumn{5}{|c|}{ Downstream } \\
\hline Transportation & Transportation load & 1.059 & $\mathrm{~kg}$ & Transportation load due to packaging and EPP box \\
\hline
\end{tabular}

EPP, expanded-polypropylene; FU, functional unit; PE, polyethylene. 


\section{Life cycle impact assessment}

The potential environmental impacts were calculated using the characterisation method by associating the scale of pollutant emission to a selected characterisation factor. For this study, most impact categories were taken directly from the CML-IA baseline method (eutrophication, global warming, ozone layer depletion and abiotic depletion, elements, and fossil fuels) and CML-IA non baseline method (acidification). The water scarcity category was based on the AWARE method. Photochemical oxidation was based on ReCiPe 2008.

The impact categories used are reported in Table 3.

\section{Results and discussion}

The results refer to: i) an investigation of the environmental performance of the expanded polypropylene box from cradle to grave without considering the catering service phase (EPP box life cycle); and ii) a comparison of the catering phase based on the model performed (application of catering service model). Finally, the engineering aspects to design a sustainable catering service were considered.

\section{Expanded-polypropylene box life cycle}

As reported in Figure 2, the results of the environmental impact analysis are divided into 100\% stacked columns according to the EPP box life cycle modules.

The upstream module, which involved only EPP extraction and expansion, was not the most impactful category. According to Table 4, the most impactful categories were POX $(7.55 \mathrm{E}-03 \mathrm{~kg}$ NMVOC; $57 \%$ ) and ACD (7.93E-03 kg SO 2 eq; 47\%), whereas the least impactful category was ODP (4.86E-08 kg CFC-11 eq; 5\%). The average percentage for all impact categories was $35 \%$.

A different consideration can be made for the core module, as the most impactful category was ODP (9.10E-07 kg CFC-11 eq; $94 \%$ ). The average percentage among all impact categories was $57 \%$. The downstream module without considering the catering service phase was the least impactful in the life cycle of the product and achieved an average value of $6 \%$ for all impact categories. In order to optimize the EPP box life cycle, it was necessary to analyse in depth the specific phase in each one of the three modules, in particular in the core module, where there are more opportunities for developing mitigation actions.

Figure 3 and Table 5 show the breakdown of the modules into their phases. The transportation of EPP beads, which was the first phase of the core module, was the smallest contributor to the total impact, except for the ADE impact category, in which this process accounts for $27 \%$ (4.04E- $07 \mathrm{~kg} \mathrm{Sb}$ eq) of the impact due to the fuels and transport emissions.

The steam chest moulding phase (and pressurization phase) required a high amount of natural gas $\left(1.60 \mathrm{dm}^{3}\right)$, electricity $(1.14$

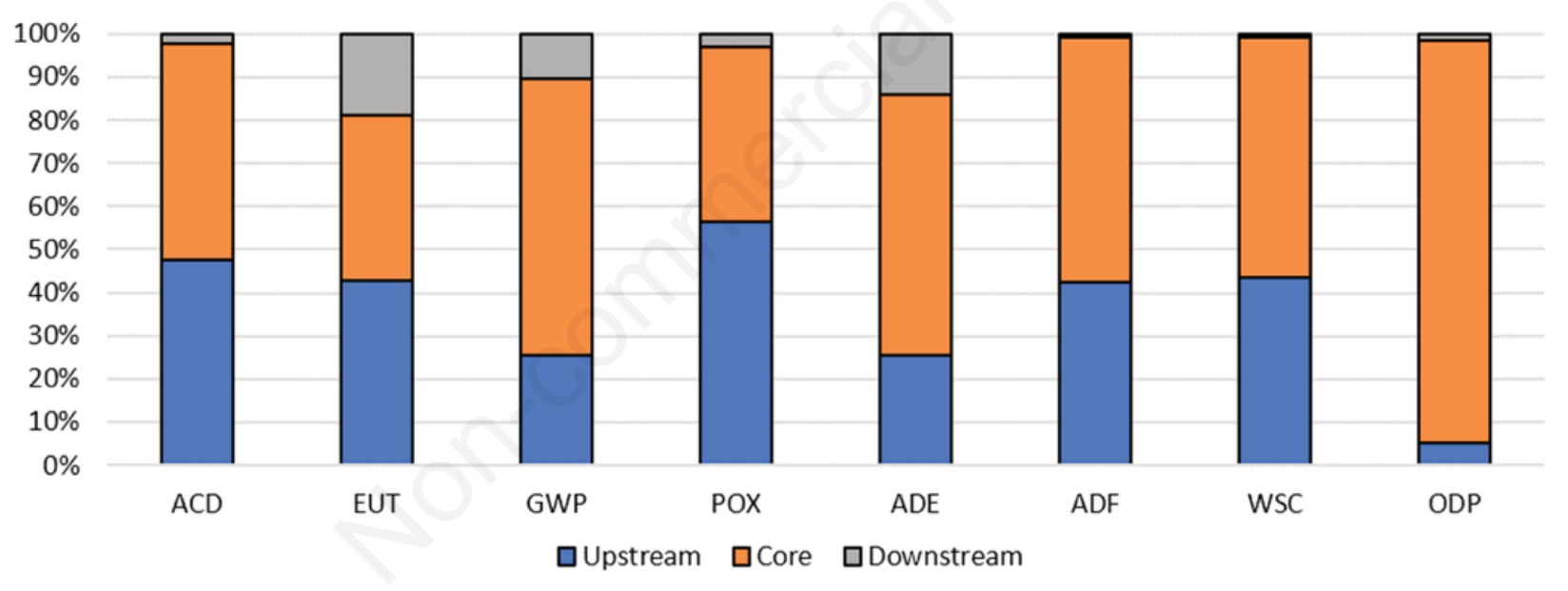

Figure 2. Contribution analysis of the expanded-polypropylene box for the upstream, core and downstream modules. ACD, acidification; EUT, eutrophication; GWP, global warming (GWP100a); POX, photochemical oxidation; ADE, abiotic depletion, elements; ADF, abiotic depletion, fossil fuels; WSC, water scarcity; ODP, ozone layer depletion.

Table 3. Impact categories, acronyms and unit of measures used in the EPD (2018) method.

\begin{tabular}{lccc} 
Impact category & Acronym & Unit measure & Characterisation factor \\
Acidification & ACD & $\mathrm{kg} \mathrm{SO}_{2}$ eq & CML 2001 \\
Eutrophication & EUT & $\mathrm{kg} \mathrm{PO}_{4}$ eq & CML 2001 \\
\hline Global warming (GWP100a) & GWP & $\mathrm{kg} \mathrm{CO}_{2}$ eq & CML 2001 \\
Photochemical oxidation & POX & $\mathrm{kg} \mathrm{NMVOC}$ & ReCiPe 2008 \\
\hline Abiotic depletion, elements & ADE & $\mathrm{kg} \mathrm{eq}$ & CML 2001 \\
Abiotic depletion, fossil fuels & ADF & $\mathrm{m}^{3}$ eq & CML 2001 \\
\hline Water scarcity & WSC & $\mathrm{kg} \mathrm{CFC}-11$ eq & AWARE \\
Ozone layer depletion & ODP & & CML 2001 \\
\hline
\end{tabular}


$\mathrm{kWh})$ and water $\left(18 \mathrm{dm}^{3}\right)$ to produce steam and pressurize the production line. For this reason, an average of $51 \%$ of the environmental footprint among all impact categories was attributable to this multi-input (natural gas, electricity and water) process. In the ACD impact category, electricity production and gas extraction account for over $42 \%$ of the total impact. In the GWP impact cat- egory, the combustion of natural gas was responsible for $87 \%$ of the steam chest moulding process which had a weight of $91 \%$. Since steam chest moulding was the most important process to produce EPP boxes, it was impossibile to eliminate. However, unlike the other phases with a lower impact, this processes offered more possibilities to optimize its environmental profile.

Table 4. Environmental impact assessment of the expanded-polypropylene box for the upstream, core and downstream modules.

\begin{tabular}{lcccc} 
Impact category & Unit of measure & Upstream & & Core \\
ACD & $\mathrm{kg} \mathrm{SO}$ eq & $7.93 \mathrm{E}-03$ & $8.44 \mathrm{E}-03$ & $3.57 \mathrm{E}-04$ \\
EUT & $\mathrm{kg} \mathrm{PO} 4 \mathrm{eq}$ & $1.84 \mathrm{E}-03$ & $1.66 \mathrm{E}-03$ & $8.06 \mathrm{E}-04$ \\
\hline GWP & $\mathrm{kg} \mathrm{CO}$ eq & 2.07 & 5.23 & $8.46 \mathrm{E}-01$ \\
POX & $\mathrm{kg} \mathrm{NMVOC}$ & $7.55 \mathrm{E}-03$ & $5.41 \mathrm{E}-03$ & $4.16 \mathrm{E}-04$ \\
\hline ADE & $\mathrm{kg} \mathrm{Sb} \mathrm{eq}$ & $3.85 \mathrm{E}-07$ & $9.22 \mathrm{E}-07$ & $2.14 \mathrm{E}-07$ \\
ADF & $\mathrm{MJ}$ & 56.20 & 75.50 & 1.14 \\
WSC & $\mathrm{m}^{3} \mathrm{eq}$ & $6.00 \mathrm{E}-01$ & $7.70 \mathrm{E}-01$ & $8.75 \mathrm{E}-03$ \\
ODP & $\mathrm{kg} \mathrm{CFC}-11 \mathrm{eq}$ & $4.86 \mathrm{E}-08$ & $9.10 \mathrm{E}-07$ & $1.36 \mathrm{E}-08$ \\
\hline
\end{tabular}

ACD, acidification; EUT, eutrophication; GWP, global warming (GWP100a); POX, photochemical oxidation; ADE, abiotic depletion, elements; ADF, abiotic depletion, fossil fuels; WSC, water scarcity; ODP, ozone layer depletion.

Table 5. Environmental impact assessment of the expanded-polypropylene box per each step studied in the system boundaries.

\begin{tabular}{|c|c|c|c|c|c|c|c|c|c|c|c|c|}
\hline $\begin{array}{l}\text { Impact } \\
\text { category }\end{array}$ & Units & $\begin{array}{l}\text { EPP bead } \\
\text { production }\end{array}$ & $\begin{array}{l}\text { EPP bead } \\
\text { transport }\end{array}$ & $\begin{array}{l}\text { EPP bead } \\
\text { storage }\end{array}$ & Filling & $\begin{array}{l}\text { Steam chest moulding } \\
\text { and pressurization }\end{array}$ & $\begin{array}{c}\text { Production } \\
\text { waste }\end{array}$ & $\begin{array}{l}\text { Thermal } \\
\text { stabilization }\end{array}$ & Packaging & $\begin{array}{l}\text { EPP box } \\
\text { transport }\end{array}$ & $\begin{array}{l}\text { End of } \\
\text { life }\end{array}$ & Total \\
\hline$A C D$ & $\mathrm{~kg} \mathrm{SO} \mathrm{eq}_{2}$ & 7.93E-03 & $4.83 \mathrm{E}-04$ & $2.76 \mathrm{E}-05$ & $1.15 \mathrm{E}-05$ & $7.80 \mathrm{E}-03$ & $2.43 \mathrm{E}-06$ & $2.92 \mathrm{E}-05$ & $8.15 \mathrm{E}-05$ & $2.42 \mathrm{E}-04$ & 1.14E-04 & 1,67E-02 \\
\hline EUT & $\mathrm{kg}_{\mathrm{PO}} \mathrm{eq}_{4}$ & $1.84 \mathrm{E}-03$ & $1.01 \mathrm{E}-04$ & $6.64 \mathrm{E}-06$ & $2.78 \mathrm{E}-06$ & $1.47 \mathrm{E}-03$ & $3.32 \mathrm{E}-05$ & 7.03E-06 & $3.29 \mathrm{E}-05$ & $5.08 \mathrm{E}-05$ & $7.55 \mathrm{E}-04$ & $4,30 \mathrm{E}-03$ \\
\hline GWP & $\mathrm{kgCO}_{2} \mathrm{eq}$ & 2.07 & $1.35 \mathrm{E}-01$ & $3.47 \mathrm{E}-03$ & $1.45 \mathrm{E}-03$ & 5.05 & 1.19E-02 & $3.67 \mathrm{E}-03$ & $2.38 \mathrm{E}-02$ & $6.77 \mathrm{E}-02$ & $7.78 \mathrm{E}-01$ & 8,14 \\
\hline POX & kg NMVOC & 7.55E-03 & $5.45 \mathrm{E}-04$ & $8.43 \mathrm{E}-06$ & $3.52 \mathrm{E}-06$ & 4.76E-03 & $3.38 \mathrm{E}-06$ & $8.92 \mathrm{E}-06$ & $8.56 \mathrm{E}-05$ & $2.73 \mathrm{E}-04$ & $1.42 \mathrm{E}-04$ & $1,34 \mathrm{E}-02$ \\
\hline $\mathrm{ADE}$ & $\mathrm{kg} \mathrm{Sb} \mathrm{eq}$ & $3.85 \mathrm{E}-07$ & 4.04E-07 & $1.53 \mathrm{E}-09$ & $6.39 \mathrm{E}-10$ & $5.04 \mathrm{E}-07$ & $3.85 \mathrm{E}-10$ & $1.62 \mathrm{E}-09$ & $9.85 \mathrm{E}-09$ & $2.03 \mathrm{E}-07$ & $1.15 \mathrm{E}-08$ & $1,52 \mathrm{E}-06$ \\
\hline $\mathrm{ADF}$ & MJ & $5.62 \mathrm{E}+01$ & 2.04 & 4.14E-02 & $1.73 \mathrm{E}-02$ & $7.28 \mathrm{E}+01$ & $2.89 \mathrm{E}-03$ & $4.38 \mathrm{E}-02$ & $5.26 \mathrm{E}-01$ & 1.02 & 1.15E-01 & $1,33 \mathrm{E}+02$ \\
\hline WSC & $\mathrm{m}^{3} \mathrm{eq}$ & $6.00 \mathrm{E}-01$ & $1.05 \mathrm{E}-02$ & $2.56 \mathrm{E}-03$ & $1.07 \mathrm{E}-03$ & 7.43E-01 & $5.92 \mathrm{E}-05$ & $2.72 \mathrm{E}-03$ & $1.09 \mathrm{E}-02$ & $5.26 \mathrm{E}-03$ & $3.49 \mathrm{E}-03$ & 1,38 \\
\hline ODP & kg CFC-11 eq & $4.86 \mathrm{E}-08$ & $2.49 \mathrm{E}-08$ & $4.03 \mathrm{E}-10$ & $1.68 \mathrm{E}-10$ & $8.83 \mathrm{E}-07$ & 3.09E-11 & 4.27E-10 & $4.58 \mathrm{E}-10$ & $1.25 \mathrm{E}-08$ & $1.11 \mathrm{E}-09$ & $9,72 \mathrm{E}-07$ \\
\hline
\end{tabular}

ACD, acidification; EUT, eutrophication; GWP, global warming (GWP100a); POX, photochemical oxidation; ADE, abiotic depletion, elements; ADF, abiotic depletion, fossil fuels; WSC, water scarcity; ODP, ozone layer depletion; EPP, expanded-polypropylene.

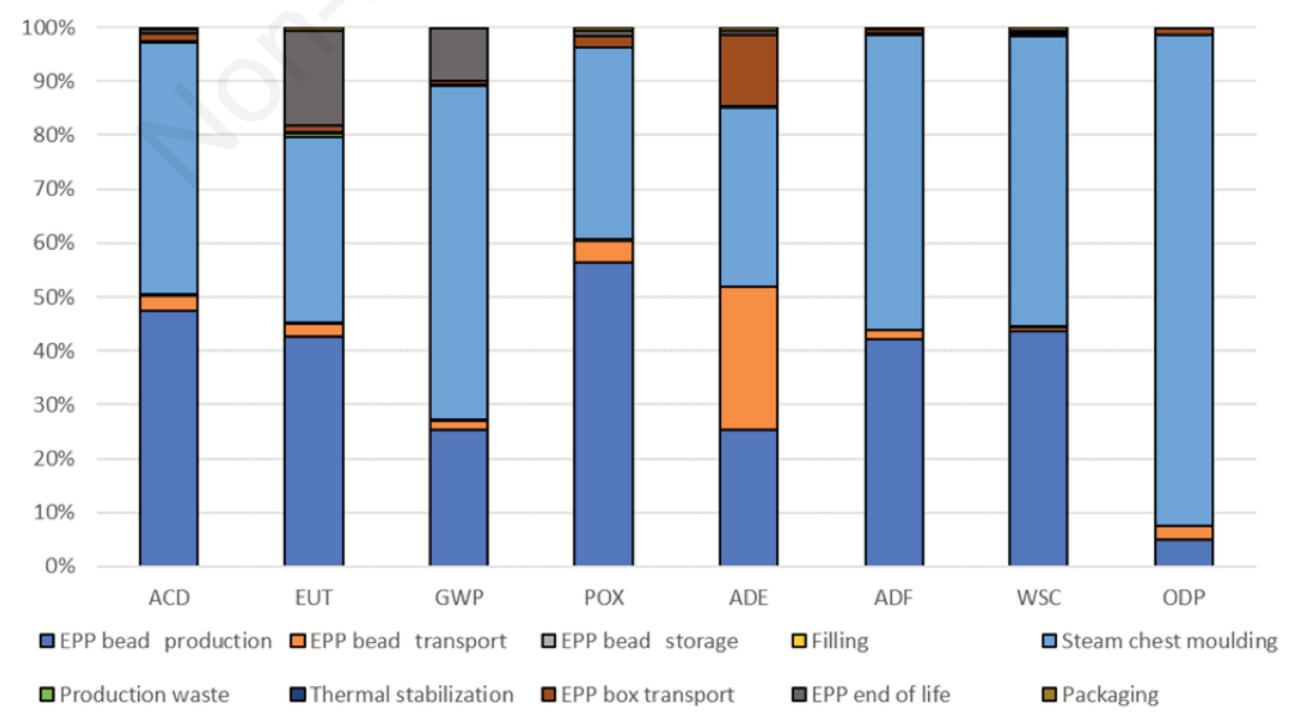

Figure 3. Contribution analysis of the EPP box for the phases included in the boundary system. ACD, acidification; EUT, eutrophication; GWP, global warming (GWP100a); POX, photochemical oxidation; ADE, abiotic depletion, elements; ADF, abiotic depletion, fossil fuels; WSC, water scarcity; ODP, ozone layer depletion; EPP, expanded-polypropylene. 
As can be seen in Figure 3 and Table 5, the transport of the EPP box and the end of life of the EPP box are not very impactful activities from the environmental point of view. The EPP box transportation from the company to the consumers only accounted for the $13 \%$ in terms of ADE impact category, while the end of life represents the major responsible phase $(31 \%)$ in the impact category EUT due to the waste management operation (7.55E-04 $\mathrm{kg} \mathrm{PO}_{4} \mathrm{eq}$ ).

\section{Scenario analysis}

Considering the impact of the core module and the most impactful activities in this module are steam chest moulding and pressurization (Figure 3 and Table 5), the first sensitivity analysis aimed at identifying the potential change in its impact assessment compared to the current scenario, if the country electricity mix were based only on renewable energy. The second parameter is related to the end of life of the EPP box, which was replaced with a scenario based on $100 \%$ recycling.

As shown in Figure 4, the use of an electricity mix based only on renewable energy led to a reduction in all impact categories. The variability of benefits depends on the weight of electricity in the different impact categories. The current electricity production, in the current scenario, implies a higher proportion of energy is derived from hard coal and incinerators which requires a high amount of natural gas. Less electricity production from this source translated into a lower impact for the ADE category, which was $36 \%$, and the increase in the use of hydropower electricity production from an alpine river led to $83 \%$ benefit for the WSC impact category. The same results were not achieved changing waste management system, apart from the EUT impact category (-18\%). The cut-off allocation criteria implied that the benefit of recycling is not attributable to the EPP box, because the gate of the recycling system, i.e. the grave of the boundary system studied, ended at the gate of the waste processing site. The last column identifies the optimal life cycle of the EPP box when it is produced with $100 \%$ renewable electricity and disposed as $100 \%$ recycled product with an overall benefit of $25 \%$.

\section{Comparative analysis}

Table 6 reports the environmental impact comparison between the EPP box and a common box used for catering services as modelled in paragraph 2.4. The catering service model analysed was based on the same variables: i) number of meals served every day; ii) food weight (products and trays); iii) distance covered in kilometres; and iv) the vehicle used (light commercial vehicle). The only variable which was changed was the weight of the box. Since there was a direct correlation between the transported load and fuel consumption, the transport of EPP generated less pollution with respect to a catering service based on $\mathrm{PE}$ with an overall benefit of $-37 \%$ (the average among multiple impact categories). As to the GWP impact category, the change in the packaging box used in the delivery system avoided the release of $88.93 \mathrm{~kg}$ of $\mathrm{CO}_{2}$ eq per year (Table 6). Potential solutions to reduce the environmental impact of catering services could be: i) high-cost investments, i.e. greener company vehicles, innovative equipment; and/or ii) low-cost

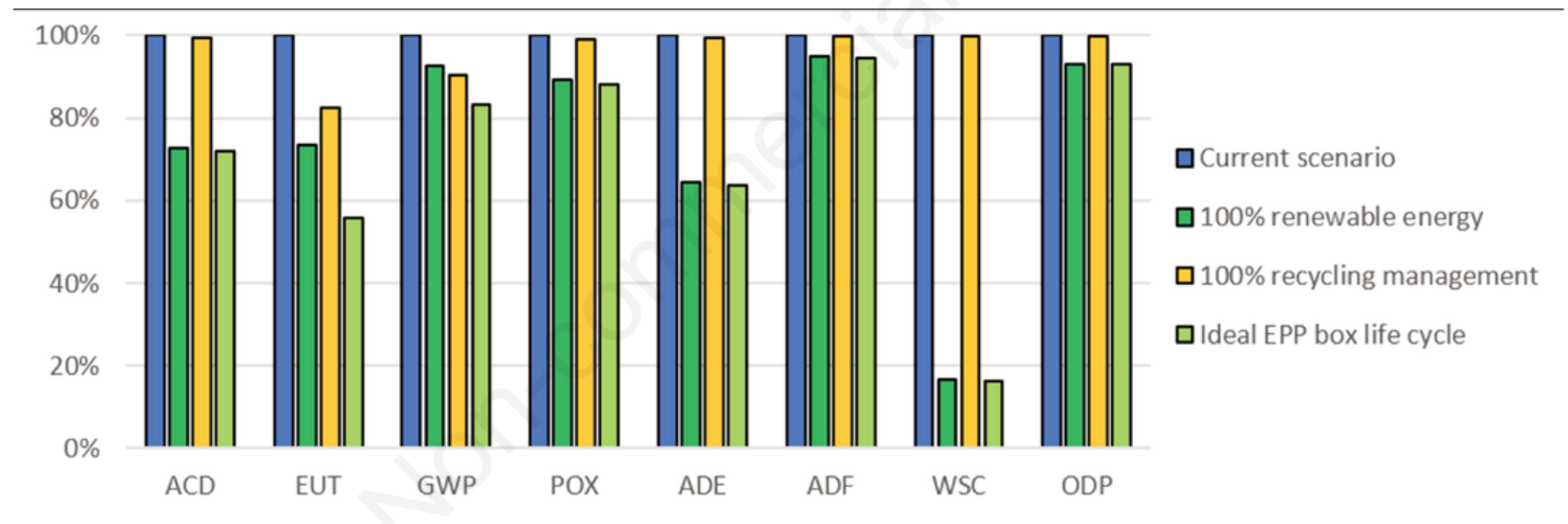

Figure 4. Sensitivity analysis resulting from the comparison between the current scenario and alternative scenarios. ACD, acidification; EUT, eutrophication; GWP, global warming (GWP100a); POX, photochemical oxidation; ADE, abiotic depletion, elements; ADF, abiotic depletion, fossil fuels; WSC, water scarcity; ODP, ozone layer depletion; EPP, expanded-polypropylene.

Table 6. Environmental impact comparison of the delivery phase.

\begin{tabular}{|c|c|c|c|c|c|}
\hline Impact category & Units & EPP box (life cycle) & EPP box (delivery phase) & Common box (delivery phase) & Delta (delivery phase) \\
\hline ACD & $\mathrm{kg} \mathrm{SO}_{2} \mathrm{eq}$ & $1.67 \mathrm{E}-02$ & 0.75 & 1.19 & -0.44 \\
\hline EUT & $\mathrm{kg}_{\mathrm{PO}} \mathrm{eq}$ & $4.30 \mathrm{E}-03$ & 0.20 & 0.32 & -0.12 \\
\hline GWP & $\mathrm{kg} \mathrm{CO} 2 \mathrm{eq}$ & 8.14 & 151.47 & 240.40 & -88.93 \\
\hline POX & kg NMVOC & $1.34 \mathrm{E}-02$ & 0.92 & 1.46 & -0.54 \\
\hline $\mathrm{ADE}$ & $\mathrm{kg} \mathrm{Sb} \mathrm{eq}$ & $1.52 \mathrm{E}-06$ & $5.92 \mathrm{E}-04$ & $9.39 \mathrm{E}-04$ & $-3.47 \mathrm{E}-04$ \\
\hline $\mathrm{ADF}$ & MJ & $1.33 \mathrm{E}+02$ & 2215.76 & 3516.69 & -1300.93 \\
\hline WSC & $\mathrm{m}^{3} \mathrm{eq}$ & 1.38 & 14.93 & 23.70 & -8.77 \\
\hline ODP & $\mathrm{kg}$ CFC-11 eq & $9.72 \mathrm{E}-07$ & $2.64 \mathrm{E}-05$ & 4.19E-05 & $-1.55 \mathrm{E}-05$ \\
\hline
\end{tabular}

EPP, expanded-polypropylene; ACD, acidification; EUT, eutrophication; GWP, global warming (GWP100a); POX, photochemical oxidation; ADE, abiotic depletion, elements; ADF, abiotic depletion, fossil fuels; WSC, water scarcity; ODP, ozone layer depletion. 
investments, i.e. reduction of food serves, fewer kilometres covered, a more efficient cooking process. Considering the limit of companies to afford high-cost investments, the reduction of food serves or the reduction of distances covered in kilometres could imply a reduction in term of revenues.

The potential use of the EPP box for food delivery could contribute to highlight the importance of engineering aspects and design a more sustainable catering service thanks to a $-37 \%$ of overall environmental benefit in the proposed LCA with respect to the respected to the use of common boxes. The results demonstrating that the EPP production process can be further improved in terms of environmental sustainability are as follows: i) changing the energy country mix ( $-25 \%$ average of category impact); ii) recycling $100 \%$ of EPP boxes, thus designing a circular economy model $(-4 \%$ average of category impact); iii) identification of more energy-saving machinery to reduce the thermal energy and electricity required.

\section{Conclusions}

The current period is characterized by an increase of the population and an increase of production in food sector. Therefore, the increase of the environmental impact derived from this growth is becoming a worldwide issue. Hence, it is necessary to apply decoupling strategies to reduce the environmental impact of products and services, continuously offering to the population the primary goods as food products. New materials and products start to become a valid alternative to traditional equipment in the logistic sector. Expanded polypropylene represents a useful solution for environmentally sustainable catering services due to its mechanical response and the insulating properties of the polymer foam. Moreover, it is suitable for packaging more sensitive goods and foodstuff. The life cycle assessment was used as a decision-making tool to calculate the environmental impact of potential options for catering service design. The potential use of EPP boxes for food delivery could be the right solution for designing sustainable catering services, because it offers a $-37 \%$ overall benefit, with respect to the use of common boxes, as shown in the proposed LCA, thus avoiding the release of $88.93 \mathrm{~kg}$ of $\mathrm{CO}_{2}$ eq.

Moreover, the environmental impact of catering services can be further optimized by changing the country energy mix in the EPP box production process and making fully recyclables EPP boxes.

\section{References}

Baldwin C., Wilberforce N., Kapur A. 2011. Restaurant and food service life cycle assessment and development of a sustainability standard. Int. J. Life Cycle Assess. 16:40-9.

Balzaretti C.M., Ventura V., Ratti S., Ferrazzi G., Spallina A., Carruba M.O., Castrica M. 2018. Improving the overall sustainability of the school meal chain: the role of portion sizes. Eat. Weight. Disord. 1-10.

Cerutti A.K., Ardente F., Contu S., Donno D., Beccaro G.L. 2018. Modelling, assessing, and ranking public procurement options for a climate-friendly catering service. Int. J. Life Cycle Assess. 23:95-115.

Cerutti A.K., Contu S., Ardente F., Donno D., Beccaro G.L. 2016. Carbon footprint in green public procurement: Policy evaluation from a case study in the food sector. Food Policy 58:8293.

Ciappellano S., Foschino R.C., Giovanelli G., Giubilesi M.A.,
Guidetti R., Lavelli V., Montanari A., Porrini M. 2009. Manuale della ristorazione: management, progettazione dei pasti, nutrizione, igiene, merceologia, tecnologia, legislazione. Ed. Casa Editrice Ambrosiana, Distribuzione Zanichelli, Bologna, Italia.

EPD. 2008. General programme instructions for environmental product declarations. Available from: http://www. environdec.com/documents/pdf/EPD_instructions_080229.pdf

European Union. 2004. Regulation (EC) No 1935/2004 of the European Parliament and the Council of 27 October 2004 on materials and objects intended to come into contact with food and repealing Directives 80/590/EEC and 89/109/EEC. O. J. Eur. Union 4-17.

FERCO. 2014. European Industry Overview. Food Service Europe. Available from: www.foodserviceeurope.org/

Fusi A., Guidetti R., Azapagic A. 2016. Evaluation of environmental impacts in the catering sector: the case of pasta. J. Clean. Prod. 132:146-60.

García-Herrero L., De Menna F., Vittuari M. 2019. Food waste at school. The environmental and cost impact of a canteen meal. Waste Manage. 100:249-58.

Giordano P., Caputo P., Vancheri A. 2014. Fuzzy evaluation of heterogeneous quantities: measuring urban ecological efficiency. Ecol. Model. 288:112-26.

ISO 14040. 2006. Environmental management - life cycle assessment - principles and framework. International Organisation for Standardisation, Geneva, Switzerland.

ISO 14044. 2006. Environmental management - life cycle assessment - requirements and guidelines, International Organisation for Standardisation, Geneva, Switzerland.

ISO 668. 2020. Series 1 freight containers - Classification, dimensions and ratings, International Organisation for Standardisation, Geneva, Switzerland.

Licciardello F, 2017. Packaging, blessing in disguise. Review on its diverse contribution to food sustainability. Trends Food Sci. Tech. 65:32-9.

Lopes J.A., Tsochatzis E.D., Robouch P., Hoekstra E. 2019. Influence of pre-heating of food contact polypropylene cups on its physical structure and on the migration of additives. Food Packag. Shelf Life 20:100305.

Manzini R., Accorsi R. 2013. The new conceptual framework for food supply chain assessment. J. Food Eng. 115:251-63.

Mistretta M., Caputo P., Cellura M., Cusenza M.A. 2019. Energy and environmental life cycle assessment of an institutional catering service: an Italian case study. Sci. Total Environ. 657:1150-60.

Morton D.T., Reyes A., Clausen A.H., Hopperstad O.S. 2020. Mechanical response of low density expanded polypropylene foams in compression and tension at different loading rates and temperatures. Mater. Today Commun. 100917.

Neto B., Boyano A., Espinosa N., Quintero R.R., Wolf O. 2017. Revision of the EU GPP criteria for Food procurement and Catering services, 3rd Technical Report. JRC Science for Policy Report, European Commission.

Palacios-Argüello L., Gonzalez-Feliu J., Gondran N., Badeig F. 2018. Assessing the economic and environmental impacts of urban food systems for public school canteens: case study of Great Lyon Region. Eur. Transp. Res. Rev. 10:37.

PlasticsEurope. 2018. Annual Review 2017-2018 - Karl-H. Foerster executive director of PlasticsEurope. Association of Plastic Manufactures.

Raps D., Köppl T., De Anda A.R., Altstädt V. 2014. Rheological and crystallisation behaviour of high melt strength polypropylene under gas-loading. Polymer 55:1537-45.

Roy P., Nei D., Orikasa T., Xu Q., Okadome H., Nakamura N., 
Shiina T. 2009. A review of life cycle assessment (LCA) on some food products. J Food Eng 90:1-10.

Saxe H., Jensen J.D., Laugesen S.M.B., Bredie W.L. 2019. Environmental impact of meal service catering for dependent senior citizens in Danish municipalities. Int J Life Cycle Assess 24:654-66.

Silva V.L., Sanjuán N. 2019. Opening up the black box: A systematic literature review of life cycle assessment in alternative food processing technologies. J. Food Eng. 250:33-45.

Srivastava V., Srivastava R. 2014. A review on manufacturing, properties and application of expanded polypropylene. MIT Int. J. Mech. Eng. 4:22-8.

Williams P.G., DipNutrDiet M.H.P. 1996. Vitamin retention in cook/chill and cook/hot-hold hospital foodservices. J. Am.
Diet. Assoc. 96:490-8.

Xu Z.M., Jiang X.L., Liu T., Hu G.H., Zhao L., Zhu Z.N., Yuan W.K. 2007. Foaming of polypropylene with supercritical carbon dioxide. J. Supercrit. Fluids. 41:299-310.

Yu L., Zhu Q., Yu J. 2013. Development and application of expanded polypropylene foam. J. Wuhan Univ. Technol. 28:373-9.

Zhai W., Kim Y.W., Park C.B. 2010. Steam-chest molding of expanded polypropylene foams. 1. DSC simulation of bead foam processing. Ind. Eng. Chem. Res. 49:9822-9.

Zhai W., Kim Y.W., Jung D.W., Park C.B. 2011. Steam-chest molding of expanded polypropylene foams. 2. Mechanism of interbead bonding. Ind. Eng. Chem. Res. 50:5523-31. 